\title{
13-15 METŲ LEDO RITULININKŲ BENDROJO FIZINIO PARENGTUMO KAITA PER METINIUS CIKLUS
}

\author{
Gracijus Girdauskas, Birutė Girdauskienė, Rimas Kazakevičius \\ Lietuvos kūno kultūros akademija, Kaunas, Lietuva
}

Gracijus Girdauskas. Docentas socialinių mokslų daktaras. Lietuvos kūno kultūros akademijos Sportinių žaidimų katedros docentas. Mokslinių tyrimų kryptis - jaunujų sportininkų rengimas ir valdymas.

\begin{abstract}
SANTRAUKA
Labai svarbu visais sportinio rengimo etapais reguliariai nustatyti ir ivertinti sportininku fizini parengtuma. Tai yra sportinio rengimo esmé (Karoblis, 2003). Pagal tyrimu rezultatus galima planuoti fizinius krūvius ateityje. Ypač svarbu deramai panaudoti treniruotès metodus ir priemones bei tinkamu santykiu taikyti Łvairias rengimo rüšis pubertatiniu jaunuju sportininku rengimo laikotarpiu (Gailiünienè, Kontvainis, 1994).

Tyrimo tikslas - nustatyti ir ivertinti 13-15 metu ledo ritulininku bendrojo fizinio parengtumo kaita per makrocikla taikant specialu triju mikrociklu rengimo planq. Buvo tirtas ledo ritulio komandos žaidèju $(n=17)$ bendrasis fizinis parengtumas, kai jiems buvo 13, 14 ir 15 metu (I-III tyrimas), analizuojant 2002 / 2003, 2003 / 2004 ir 2004 / 2005 metu sezonu tyrimo rezultatu vidurkius. Fiziniam parengtumui ištirti naudota New Test elektroninè aparatūra. Tyrimo metu nustatème greituma, jègos greituma, staigiaja jèga (Bosco et al., 1983; Raslanas, Skernevičius, 1998). Tiriamieji atliko po tris bandymus, užrašomas tik geriausias rezultatas. Taip pat buvo nustatyta jègos ištvermé, ištvermé, plaštakujèga (dinamometrija), vikrumas (specialusis testas).

Fiziniu ypatybiu pokyčiai per tyrimo laikotarpi buvo šie: staigiosios jègos (horizontalaus šuolio $-10,7 \%$, vertikalaus - 9,7\%); greitumo - 8,6\%; jègos greitumo (30 m bègimo iš vietos - 4,6\%, $20 \mathrm{~m}-4,0 \%$ ); plaštakos jègos (dinamometrijos): dešinès - 27\%, kairés - 26\%; jègos ištvermés (prisitraukimu prie skersinio) - 22\%; vikrumo (specialiojo testo) - 6,4\%; ištvermes (300 m bègimo) - 12\%. Tyrimo rezultatai leidžia teigti, kad mūsu naudota eksperimentiné fizinio rengimo programa buvo veiksminga. Lygindami Lietuvos 13-15 metu ledo ritulininku ivairiu fiziniu ypatybiu rezultatus su kitu šaliu (Švedijos, Rusijos) ir Lietuvos šio amžiaus krepšininku analogišku tyrimu fizinio parengtumo rezultatais galime teigti, kad buvo geresni müsu tiriamuju staigiosios jëgos, greitumo fiziniu ypatybiu rezultatai, o ištvermès, jëgos ištvermès ir vikrumo fiziniu ypatybiu — panašüs.
\end{abstract}

Raktažodžiai: rengimo etapai, rengimo rūšys, tyrimo laikotarpis, mezociklas, metinis ciklas.

\section{IVADAS}

$\mathrm{S}$ portinio rengimo metu labai svarbu tinkamai parinkti ir išdèstyti fizinius krūvius, jų santyki su kitomis rengimo rūšimis. $\mathrm{Ne}$ mažiau svarbu sekti jaunujų sportininkų fizinès būklès, darbingumo kitimą atliekant skirtingus fizinius krūvius.

Gauti rezultatai turi būti panaudoti tolesniam krūviui planuoti. Visais sportinio rengimo etapais labai svarbu reguliariai nustatyti, ivertinti ir koreguoti sportininku parengtumą. Tai yra visos sporto treniruotès planavimo ir valdymo esmè. Pedagoginè kontrolè, sportininkų testavimo rezultatai parodo taikomų priemonių operatyvumą, tinkamumą ir efektyvumą (Karoblis, 2003). Remiantis konkrečiais tyrimų rezultatais galima planuoti fizinius krūvius ir jų taikymo metodus ateityje. Tik taip bus garantuotas tinkamas fizinis parengtumas, leidžiantis efektyviai spręsti ir kitų rengimo rūšių uždavinius. Ypač svarbu deramai panaudoti treniruotès metodus ir priemones bei 
tinkamu santykiu taikyti įvairias rengimo rūšis. Dar didesnę reikšmę fizinio rengimo metu igyja tikslingas fiziniu ypatybių lavinimo priemoniu taikymo santykis pubertatiniu jaunujų sportininku rengimo laikotarpiu (Gailiūnienè, Kontvainis, 1994). Vaikų ir paauglių atliekami didelès apimties bendrojo fizinio rengimo krūviai, neatitinkantys būsimos specializacijos reikalavimų, gali slopinti igimtus jaunujų sportininkų gabumus, gebejjimus ir neleisti ateityje pasiekti gerų rezultatu (Платонов, 2004).

Hipotezè. Manome, kad taikant tinkamas treniruotès programas ir atsižvelgiant i vaikų amžiaus palankiausius laikotarpius fizinèms ypatybèms lavinti, galima sulaukti akivaizdaus rezultatuc pagerejjimo.

Tyrimo tikslas - nustatyti $13-15$ metu ledo ritulininkų bendrojo fizinio parengtumo kaitą per metinius ciklus.

\section{Tyrimo uždaviniai:}

1. Ivertinti ledo ritulininkų fizinių ypatybių pokyčius tiriamuoju laikotarpiu (2003-2005 m.).

2. Palyginti sportinio parengtumo tyrimo rezultatus su analogiškais kitų mokslininkų atliktu tyrimų rezultatais.

\section{TYRIMO METODAI IR ORGANIZAVIMAS}

Tyrimo metu buvo taikomi šie metodai:

1. Literatūros šaltinių analizè.

2. Pedagoginis eksperimentas.

3. Testavimas.

4. Matematinè statistika: aritmetinis vidurkis, procentine absoliutaus ir santykinio pokyčio išraiška, vidutinių reikšmių skirtumo reikšmingumo nustatymas pagal Stjudento $t$ vertinimo kriterijų $(\mathrm{n}=17)$.

5. Lyginamoji analizè.

Sportinis rengimas, akcentuotas fiziniu ypatybių lavinimas, vyko pagal iš anksto parengtus planus (1 lent.) lapkričio, sausio, balandžio ir birželio mėnesiais. Jų efektyvumui įvertinti bu- vo atliekamas etapinis testavimas, pagal kurio rezultatus sportini rengimą koregavome.

Buvo tirta vaiku ledo ritulio komandos tų pačių žaidejų $(n=17)$ bendrasis fizinis parengtumas, kai jiems buvo 13, 14 ir 15 metu (I-III tyrimai), analizuojant $2002 / 2003$, 2003 / 2004 ir 2004 / 2005 metu sezonu tyrimo rezultatų vidurkius. Žaidejjų sportinis stažas $7-9$ metai.

Fiziniam parengtumui nustatyti naudota $\mathrm{New}$ Test elektroninè aparatūra. Išmatuota: greitumas (20 m bègimas ísibėgejjus), jègos greitumas ( $20 \mathrm{~m}, 30 \mathrm{~m}$ bègimas iš vietos), staigioji jèga (šuolis aukštyn mojant rankomis ant kontaktinès platformos (Bosco et al., 1983) ir šuolis $\mathfrak{i}$ toli iš vietos (Raslanas, Skernevičius, 1998)). Tiriamieji atliko po tris bandymus, užrašomas tik geriausias rezultatas. Taip pat buvo nustatyta tiriamuju jègos ištvermè (prisitraukimai prie skersinio), specialioji ištvermė (300 m bėgimas), plaštaku jèga (kairès ir dešinès plaštakos dinamometrija), vikrumas (specialusis testas, žr. 1 pav.).

Po signalo tiriamasis atlieka du $360^{\circ}$ apsisukimus kairèn ir dešinèn, du kūlvirsčius atgal ir vieną pirmyn, peršoka per $60 \mathrm{~cm}$ aukščio barjerą, pro antrą pralenda, gyvatèle apibèga šešias kliūtis ir finišuoja atbulomis (1 pav.).

Sezonu metu buvo taikoma bendrojo fizinio rengimo eksperimentinè programa (1 lent.).

\section{REZULTATAI}

Iš pateiktų tyrimo rezultatų (2 lent.) matyti, kad kiekvienais metais jaunujų ledo ritulininkų bendrojo fizinio parengtumo rezultatai gerejo, tačiau nevienodai. 14 metų amžiaus sportininkų rezultatai buvo geriausi II testavimo metu (2003 / 2004 m.): pastebimi jègos (plaštakų dinamometrijos) ir jègos ištvermès (prisitraukimu prie skersinio) ypatybiu lavejjimas. Mažiau kito jègos greitumo (30 ir $20 \mathrm{~m}$ bėgimo iš vietos) ir vikrumo (specialiojo testo) fizinių ypatybių rezultatai.

Lyginant II ir III testavimo rezultatus matyti,

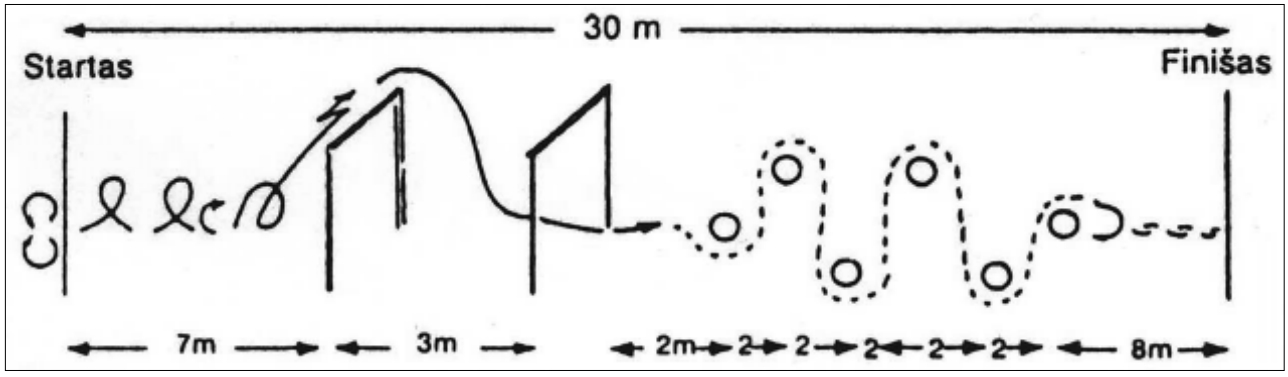

1 pav. Testas vikrumui nustatyti (schema) 


\begin{tabular}{|c|c|c|c|c|}
\hline $\begin{array}{l}1 \text { lentelè. } 13-15 \text { m. ledo } \\
\text { ritulininkų bendrojo fi- } \\
\text { zinio rengimo mezoci- } \\
\text { klo ( } 3 \mathrm{MKC} \text { ) planas }\end{array}$ & Dienos & I & II & III \\
\hline & Pirmadienis & $\begin{array}{l}\text { Staigiosios jëgos lavinimas } \\
\text { akcentuojant jègq. } \\
\text { Vyrauja vienkartinio rau- } \\
\text { mens susitraukimo prati- } \\
\text { mai: vertikalūs ir horizon- } \\
\text { talūs šuoliai iš vietos. }\end{array}$ & $\begin{array}{l}\text { Staigiosios jègos lavinimas } \\
\text { akcentuojant greitumo jëgq. } \\
\text { Vyrauja vienkartinio raumens } \\
\text { susitraukimo pratimai: } \\
\text { vertikalūs ir horizontalūs } \\
\text { šuoliai įsibėgejjus } 3-5 \\
\text { žingsnius, atsispiriant abiem } \\
\text { kojom. }\end{array}$ & $\begin{array}{l}\text { Staigiosios jëgos lavinimas } \\
\text { akcentuojant greitumq. } \\
\text { Vyrauja vertikalūs ir hori- } \\
\text { zontalūs šuoliai nuo gim- } \\
\text { nastikos tiltelio i̇sibègèjus } \\
3-5 \text { žingsnius. }\end{array}$ \\
\hline & Antradienis & $\begin{array}{l}\text { Koordinaciniu gebejjimu } \\
\text { (pratimai ant čiužinių su } \\
\text { kamuoliais, prie gimnasti- } \\
\text { kos suolelio) ir ištvermés } \\
\text { lavinimas ( } 30 \text { min bėgi- } \\
\text { mas). Pulsas - } 130- \\
140 \text { tv. / min. }\end{array}$ & $\begin{array}{l}\text { Aerobinis jëgos ištvermès } \\
\text { lavinimas. } \\
\text { Pratimai raižytoje vietovèje, } \\
\text { bėgimai i îkalnę, pratimai } \\
\text { poromis. Pulsas - } 130 \text { - } \\
140 \text { tv. / min. }\end{array}$ & $\begin{array}{l}\text { Jègos ištvermés lavinimas. } \\
\text { Ivairūs klaidinamieji, imi- } \\
\text { taciniai žaidimo kūnu ju- } \\
\text { desiais, partnerio pernešimo } \\
\text { pratimai bègant i ṫkalnę. } \\
\text { Pulsas - 140- } \\
150 \text { tv. / min. }\end{array}$ \\
\hline & Trečiadienis & $\begin{array}{l}\text { Staigiosios jëgos lavinimas } \\
\text { akcentuojant jëgq. } \\
\text { Vyrauja vienkartinio rau- } \\
\text { mens susitraukimo prati- } \\
\text { mai: vertikalūs ir horizon- } \\
\text { talūs šuoliai iš vietos. Pra- } \\
\text { timai su svarmenimis } \\
\text { (2 ser. po } 4 \text { kartus) visoms } \\
\text { raumenų grupèms. Pratybų } \\
\text { pabaigoje — koordinaci- } \\
\text { niai pratimai. }\end{array}$ & 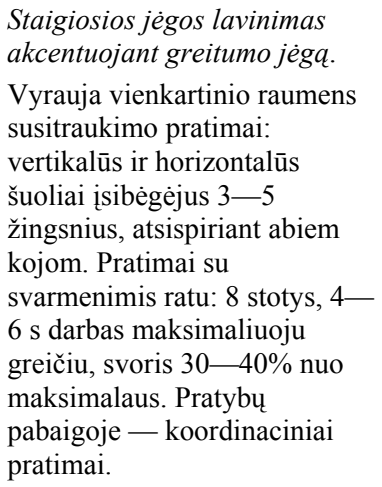 & $\begin{array}{l}\text { Staigiosios jejgos lavinimas } \\
\text { akcentuojant greituma. } \\
\text { Vyrauja vertikalūs ir hori- } \\
\text { zontalūs šuoliai nuo gim- } \\
\text { nastikos tiltelio isibègèjus } \\
3-5 \text { žingsnius. Pratimai su } \\
\text { svarmenimis ratu: } 8 \text { stotys, } \\
4-6 \text { s darbas maksi- } \\
\text { maliuoju greičiu, svoris } \\
20-30 \% \text { nuo maksimalaus. } \\
\text { Pratybu pabaigoje — koor- } \\
\text { dinaciniai pratimai. }\end{array}$ \\
\hline & Ketvirtadienis & $\begin{array}{l}\text { Koordinaciniu gebejimu } \\
\text { (pratimai ir žaidimai su } \\
\text { futbolo kamuoliais) ir ǐ̌- } \\
\text { tvermés lavinimas ( } 30 \mathrm{~min} \\
\text { bėgimas). Pulsas - } 130- \\
140 \mathrm{tv} . / \mathrm{min} .\end{array}$ & $\begin{array}{l}\text { Aerobinis jègos ištvermès } \\
\text { lavinimas. } \\
\text { Pratimai raižytoje vietoveje, } \\
\text { bėgimai i ikalnę, pratimai } \\
\text { poromis. Pratimai ir žaidimai } \\
\text { su krepšinio kamuoliais. } \\
\text { Pulsas - } 130-140 \mathrm{tv} \text {. / min. }\end{array}$ & $\begin{array}{l}\text { Jégos ištvermés ir ištvermés } \\
\text { lavinimas. } \\
\text { Jėgos pratimai poromis ir } \\
\text { trejetais bėgant i̇ikalnę. Iš- } \\
\text { tvermès - bėgimo koordi- } \\
\text { naciniai pratimai su kliūti- } \\
\text { mis. Pulsas - 130- } \\
140 \text { tv. / min. }\end{array}$ \\
\hline & Penktadienis & $\begin{array}{l}\text { Staigiosios jëgos lavinimas } \\
\text { akcentuojant jejgq. } \\
\text { Vyrauja vienkartinio rau- } \\
\text { mens susitraukimo prati- } \\
\text { mai: maksimalūs vertikalūs } \\
\text { ir horizontalūs šuoliai } \\
\text { nušokus nuo } 30-40 \mathrm{~cm} \\
\text { pakylos. Pratimai su svar- } \\
\text { menimis ( } 2 \text { ser. po } 4 \text { kar- } \\
\text { tus) visoms raumenu gru- } \\
\text { pems. Pratybu pabaigo- } \\
\text { je - koordinaciniai prati- } \\
\text { mai. }\end{array}$ & $\begin{array}{l}\text { Staigiosios jëgos lavinimas } \\
\text { akcentuojant greitumo jëga. } \\
\text { Vyrauja vienkartinio raumens } \\
\text { susitraukimo pratimai: } \\
\text { maksimalūs vertikalūs ir } \\
\text { horizontalūs šuoliai nušokus } \\
\text { nuo } 20 \text {-30 cm pakylos. } \\
\text { Pratimai su svarmenimis ratu: } \\
8 \text { stotys, darbas } 4-6 \mathrm{~s} \\
\text { maksimaliuoju greičiu, svoris } \\
20-30 \% \text { nuo maksimalaus. } \\
\text { Pratybu pabaigoje- ko- } \\
\text { ordinaciniai pratimai. }\end{array}$ & $\begin{array}{l}\text { Staigiosios jëgos lavinimas } \\
\text { akcentuojant greituma. } \\
\text { Koordinaciniai akrobatikos } \\
\text { pratimai: posūkiai, kūlvirs- } \\
\text { čiai. Pagreitejjimai i nuo- } \\
\text { kalnę, pliometriniai šuoliai } \\
\text { didèjant kliūties aukščiui (3 } \\
\text { kliūtys). Akcentuojamas } \\
\text { pratimo atlikimo greitis. } \\
\text { Pratybu pabaigoje — koor- } \\
\text { dinaciniai pratimai. }\end{array}$ \\
\hline
\end{tabular}

kad labiausiai pakito jègos ypatybès (plaštakų dinamometrijos) ir jègos ištvermès (prisitraukimu prie skersinio) rezultatai. Mažiausiai pakito, kaip rodo ir ankstesni tyrimai, jègos greitumo rezultatai.

Viso tyrimo metu didžiausi pokyčiai pastebimi jègos ir jègos ištvermès, o mažiausi — jègos greitumo ypatybių rezultatų.

\section{REZULTATU ANALIZE்}

Per tyrimo laikotarpi ledo ritulininkų bendrojo fizinio parengtumo rezultatai gerèjo, tačiau i̇vairios fizinès ypatybès kito nevienodai.

Didžiausias rezultatų gerejjimas (2 lent.) tarp I ir II tyrimo pastebimas šiu fiziniu ypatybių: jègos ištvermès (prisitraukimų prie skersinio) santykinis 


\begin{tabular}{|c|c|c|c|c|c|c|c|c|c|c|c|}
\hline $\begin{array}{l}\quad \text { Rodiklis } \\
\text { Metai } \\
\text { (sezonas), } \\
\text { tyrimas }\end{array}$ & $\begin{array}{l}30 \mathrm{~m} \\
\text { bègi- } \\
\text { mas iš } \\
\text { vietos }\end{array}$ & $\begin{array}{l}20 \mathrm{~m} \\
\text { bègi- } \\
\text { mas iš } \\
\text { vietos }\end{array}$ & $\begin{array}{l}20 \mathrm{~m} \\
\text { bègi- } \\
\text { mas } \\
\text { jsibè- } \\
\text { gèjus }\end{array}$ & $\begin{array}{l}\text { Šuolis í } \\
\text { toli iš } \\
\text { vietos }\end{array}$ & $\begin{array}{l}\text { Šuolis } \\
\text { aukš- } \\
\text { tyn } \\
\text { mojant } \\
\text { ranko- } \\
\text { mis }\end{array}$ & $\begin{array}{l}\text { Plašta- } \\
\text { kos di- } \\
\text { namo- } \\
\text { metrija } \\
\text { (D) }\end{array}$ & $\begin{array}{l}\text { Plašta- } \\
\text { kos di- } \\
\text { namo- } \\
\text { metrija } \\
(\mathrm{K})\end{array}$ & $\begin{array}{l}\text { Vikru- } \\
\text { mo tes- } \\
\text { tas }\end{array}$ & $\begin{array}{l}300 \mathrm{~m} \\
\text { bègi- } \\
\text { mas }\end{array}$ & $\begin{array}{l}\text { Prisi- } \\
\text { trau- } \\
\text { kimai }\end{array}$ & $\begin{array}{l}2 \text { lentelè. } 13-15 \text { me- } \\
\text { tụ ledo ritulininku } \\
2002 / 2003,2003 / 2004 \\
\text { ir } 2004 / 20005 \text { metų se- } \\
\text { zonų bendrojo fizinio } \\
\text { parengtumo rezultatai }\end{array}$ \\
\hline \multicolumn{11}{|l|}{$\begin{array}{l}2002 / 2003 \\
I\end{array}$} & \\
\hline Vidurkis & 4,77 & 3,39 & 2,91 & 2,17 & 42,7 & 30 & 20 & 18,3 & 54,09 & 7,4 & \\
\hline \multicolumn{11}{|l|}{$\begin{array}{l}2003 / 2004 \\
I I\end{array}$} & \\
\hline Vidurkis & 4,68 & 3,31 & 2,80 & 2,28 & 45,1 & 35 & 33 & 17,7 & 51,44 & 8,8 & \\
\hline $\begin{array}{l}\text { Absoliutus } \\
\text { skirtumas }\end{array}$ & 0,09 & 0,08 & 0,11 & 0,11 & 2,4 & 5 & 13 & 0,6 & 2,65 & 1,4 & \\
\hline $\begin{array}{l}\text { Santykinis } \\
\text { skirtumas } \\
\text { tarp I ir II, } \\
\%\end{array}$ & 1,9 & 2,4 & 3,9 & 4,8 & 5,3 & 14,3 & 39,4 & 3,4 & 5,2 & 15,9 & \\
\hline $\mathrm{p}$ & $>0,05$ & $>0,05$ & $<0,05$ & $<0,05$ & $>0,05$ & $<0,001$ & $<0,001$ & $<0,001$ & $<0,05$ & $>0,05$ & \\
\hline \multicolumn{11}{|l|}{$\begin{array}{l}2004 / 2005 \\
\text { III }\end{array}$} & \\
\hline Vidurkis & 4,56 & 3,26 & 2,68 & 2,43 & 47,3 & 41 & 38 & 17,2 & 48,3 & 9,5 & \\
\hline $\begin{array}{l}\text { Absoliutus } \\
\text { skirtumas }\end{array}$ & 0,12 & 0,05 & 0,12 & 0,15 & 2,2 & 6 & 5 & 0,5 & 3,14 & 0,7 & \\
\hline $\begin{array}{l}\text { Santykinis } \\
\text { skirtumas } \\
\text { tarp II ir III, } \\
\%\end{array}$ & 2,6 & 1,5 & 4,5 & 6,2 & 4,7 & 14,6 & 13,2 & 2,9 & 6,5 & 7,4 & \\
\hline $\mathrm{p}$ & $>0,05$ & $>0,05$ & $<0,05$ & $<0,001$ & $>0,05$ & $<0,05$ & $>0,05$ & $<0,05$ & $<0,001$ & $<0,05$ & \\
\hline $\begin{array}{l}\text { Absoliutus } \\
\text { skirtumas } \\
\text { tarp I ir III }\end{array}$ & 0,21 & 0,13 & 0,23 & 0,26 & 4,6 & 11 & 10 & 1,1 & 5,79 & 2,1 & \\
\hline $\begin{array}{l}\text { Santykinis } \\
\text { skirtumas } \\
\text { tarp I ir III, } \\
\%\end{array}$ & 4,6 & 4,0 & 8,6 & 10,7 & 9,7 & 27 & 26 & 6,4 & 12 & 22 & \\
\hline $\mathrm{p}$ & $<0,001$ & $<0,05$ & $<0,001$ & $<0,001$ & $<0,05$ & $<0,001$ & $<0,001$ & $<0,001$ & $<0,001$ & $<0,05$ & \\
\hline
\end{tabular}

rezultatu gerejjimas sudaro $15,9 \%$, tačiau jis nėra statistiškai patikimas $(p>0,05)$; plaštakos jègos (dinamometrijos) rezultatu prieaugis: dešinès plaštakos - 14,3\%, kairès - 39,4\% $(\mathrm{p}<0,001)$; staigiosios jègos: horizontalaus šuolio $-4,8 \%$, $(\mathrm{p}<0,05)$, vertikalaus - 5,3\% $(\mathrm{p}>0,05)$; specialiosios ištvermès - 5,2\% $(\mathrm{p}<0,05)$.

Mažiau pagerèjo greitumo - 3,9\% $(\mathrm{p}<0,05)$, vikrumo $-3,4 \%(\mathrm{p}<0,001)$, jègos greitumo (20 ir $30 \mathrm{~m}$ bègimo iš vietos) $-1,9 \%$ ir $2,4 \%$ $(p>0,05)$ fizinès ypatybès.

Lyginant šio amžiaus Lietuvos ledo ritulininku staigiosios jègos (horizontalaus šuolio) testavimo rezultatus su Švedijos ledo ritulininkų modelinèmis charakteristikomis (Ischockeyspelares fisika training, 2002) galima teigti, kad Lietuvos sportininku rezultatai yra geresni (atitinkamai 2,28 ir $1,77 \mathrm{~m}$ ), taip pat jie geresni lyginant su Rusijos ledo ritulininkų tokio amžiaus sportininkų tyrimų rezultatais (Быстров, 2000). Rusijos ledo ritulininkų $-2,01 \mathrm{~m}$, mūsų grupès $-2,28 \mathrm{~m}$. Geresni ir mūsų tiriamuju šuolio į aukšti mojant rankomis rezultatai.

Specialiosios ištvermès ypatybès testo rodikliai (300 m bėgimo): Rusijos ledo ritulininku rezultatas - 49,6 s, Lietuvos ledo ritulininku $48,3 \mathrm{~s}$.

Lyginant ledo ritulininku $30 \mathrm{~m}$ bègimo rezultatus su futbolininkų (FIFA) rezultatų modelinėmis charakteristikomis, mūsų 13, 14 ir 15 metų vaikų rezultatai atitinka antrą lygi. Lyginant su krepšininku greitumo tyrimo rezultatais $(\mathrm{Bu}-$ 
tautas, 2001), mūsų tirtų šio amžiaus vaikų rezultatai panašūs: $20 \mathrm{~m}$ bėgimo iš vietos (14 metų) krepšininku - 3,34 s, ledo ritulininku - 3,31.

Analizuodami II ir III tyrimo rezultatu pokyčius pastebime nevienodą rezultatu gerejjimą. Labiausiai gerejjo vaiku plaštaku jègos (dinamometrijos): $14,6 \%$ dešinès $(p<0,05)$ ir $13,2 \%$ - kairès $(p>0,05)$, mažiau jègos ištvermès (prisitraukimų prie skersinio) - 7,4\%, greitumo ištvermès (300 m bėgimo) - 6,5\%, staigiosios jègos (šuolio i toli iš vietos) $-6,2 \%$ ir jègos greitumo (20 $\mathrm{m}$ bègimo issibègèjus) $4,5 \%$ rezultatai. Visų rezultatų vidurkio skirtumas statistiškai patikimas $(\mathrm{p}<0,05)$.

Mokslininkų (Bouchard, Malina, 1994) atlikti tyrimai įrodè, kad labiausiai fizinès ypatybès gerèja tam tikru amžiaus tarpsniu: galingumo - 9-15 m. amžiaus, jègos - 13-14 m., greitumo - 9$15 \mathrm{~m}$. Vadinasi, atlikto tyrimo rezultatai sutampa su kitų mokslininkų pateiktais apie tinkamiausius greitumo, galingumo ir jègos ugdymo amžiaus tarpsnius.

Apibendrinant viso tyrimo, atlikto $2003-$ 2005 metais (I-III tyrimo), rezultatu pokyčius matome akivaizdu jų gerejimą. Taigi galima teigti, kad rengimo metu taikomos priemonès, metodai bei jų tarpusavio santykis paskirstyti deramai ir atitinka tirto amžiaus ledo ritulininkų sportinio rengimo reikalavimus.

\section{IŠVADOS}

1. Nustatyta, kad ledo ritulininkų fizinių ypatybių pokyčiai per tyrimo laikotarpi buvo:

- staigiosios jègos: horizontalaus šuolio $10,7 \%$, vertikalaus - 9,7\%;

- greitumo: $20 \mathrm{~m}$ bègimo įsibėgejjus $8,6 \%$;

- jègos greitumo: $30 \mathrm{~m}$ bègimo iš vietos 4,6\%, $20 \mathrm{~m}$ bégimo iš vietos - 4,0\%;

- plaštakos jègos (dinamometrijos): dešinès $-27 \%$, kairès $-26 \%$;

- jègos ištvermès (prisitraukimų prie skersinio) $-22 \%$;

- vikrumo (specialiojo testo) - 6,4\%;

- greitumo ištvermès (300 m bègimo) $12 \%$.

2. Analizuodami Lietuvos $13-15$ metų ledo ritulininku ivairių fiziniu ypatybių rezultatus ir lygindami juos su kitų šalių (Švedijos, Rusijos) specialistų analogiškais rezultatais galime teigti, kad mūsų tiriamujų staigiosios jègos, greitumo fiziniu ypatybių rezultatai buvo geresni, o ištvermès, jègos ištvermès ir vikrumo - panašūs.

3. Rezultatu gerejimas tyrimo metu ir jų palyginimas su kitų mokslininkų tyrimų rezultatais leidžia teigti, kad mūsų naudoti eksperimentiniai mikrociklų planai buvo veiksmingi.

\section{LITERATŪRA}

Bosco, C., Komi, P., Tihanyi, I., Fekete, G., Apor, P. (1983). Mechanical power test and fiber composition of human leg extensor muscles. European Journal of Applied Physiology, 41, 22-23.

Bouchard, C., Malina, R. M. (1997). Genetics of Fitness and Physical Performance. Human Kinetics.

Butautas, R. (2001). Vienalaikio treniruotès metodo taikymo veiksmingumas jaunujų krepšininkų techniniam parengtumui. Sporto mokslas, 1 (23), 79.

Gailiūnienė, A., Kontvainis, V. (1994). Vaiku, paaugliu ir jaunuoliu organizmo ypatumai. D. 1. Kaunas: Gabija.
Gustavson, K.-A. et al. (2002). Ishockeyspelares fysiska training. Tranigslara. Del. 2. Fysprojektet testmetodik.

Karoblis, P. (2003). Jaunojo sportininko treniruoté. Vilnius: Sporto informatikos centras. P. 222-232.

Raslanas, A., Skernevičius, J. (1998). Sportininku testavimas. Vilnius: LTOK.

Быстров, В. А. (2000). Основы обучения и тренировки юных хоккеистов. Москва: Терра спорт.

Платонов, В. Н. (2004). Система подготовки спортсменов в олимпийском спорте. Киев: Олимпийская литература. 


\title{
CHANGES IN OVERALL PHYSICAL FITNESS OF ICE-HOCKEY PLAYERS AGED 13-15 YEARS DURING ANNUAL CYCLES
}

\author{
Gracijus Girdauskas, Birutė Girdauskienė, Rimas Kazakevičius \\ Lithuanian Academy of Physical Education, Kaunas, Lithuania
}

\begin{abstract}
Regular establishing and estimation of sports fitness of athletes is of the greatest importance for the results to be achieved in all stages of sports training. This is the very essence of sports training (Karoblis, 2003). On the basis of the results of the research planning ahead of physical loads to be applied is made possible. Proper use of training methods and means, as well as selection of the proper ratio of the various kinds of training to be applied in the pubertal period of training young athletes is of utmost importance (Gailiūniene, Kontvainis, 1994). The aim of our research was to establish and estimate the changes in the macrocycle of overall physical fitness of ice-hockey players aged $13-15$ years with a special training plan of three microcycles being applied. The research was done in the overall physical fitness of children, players of ice-hockey team $(\mathrm{n}=17)$, then they were 13, 14 and 15 years old (research I-III). Mean results of the research done during the game seasons in the years 2002 / 2003, 2003/2004 and 2004 / 2005 have been presented in the present paper. The New Test electronic apparatus for establishing physical fitness has been used. Speed, force speed and explosive force (Bosco et al., 1983; Raslanas, Skernevičius, 1998), have been established. The subject were given three trials and the best result was recorded. Force, endurance, hand force (dynamometry) and agility (a special test) have been established too.

During the period of the research the following changes in physical properties have been registered: explosive force, i. e. the long / horizontal jump - 10.7\% and the high / vertical jump of $30 \mathrm{~m}$ standing run $9.7 \%$, force speed - i. e. $30 \mathrm{~m}$ standing run $-4.6 \%$ and $20 \mathrm{~m}$ run $-4.0 \%$, hand force (dynamometry), i. e. the right hand $-27 \%$ and the left hand $-26 \%$, force endurance, i. e. pull ups $-22 \%$, agility (a special test) $-6.4 \%$, and endurance ( $300 \mathrm{~m}$ run) $-12 \%$ accordingly. The results obtained allow us to assert that the experimental program of physical training applied has proved to be efficient. A comparison of the results of various physical properties of the Lithuanian 13-15 year old ice-hockey players with those of other countries (Sweden, Russia) and the respective results of the physical fitness of the Lithuanian basketball players of the same age enable us to assert that our subjects have demonstrated better results in the physical properties of explosive force and speed, whereas similar results in the physical properties of endurance, force endurance and agility have been registered.
\end{abstract}

Keywords: training stages, kinds of training, the period of training, macrocycle and microcycle, research results.

Gauta 2005 m. rugsejo $12 \mathrm{~d}$.

Received on September 12, 2005

Gracijus Girdauskas

Priimta 2005 m. gruodžio 28 d.

Lietuvos kūno kultūros akademija

Accepted on December 28, 2005

(Lithuanian Academy of Physical Education)

Sporto g. 6, LT-44221 Kaunas

Lietuva (Lithuania)

Tel +370 37302675 